\title{
PERAN TIM PENGAWAL DAN PENGAMAN PEMERINTAHAN DAN PEMBANGUNAN DAERAH DALAM UPAYA MENCEGAH TINDAK PIDANA KORUPSI DI KABUPATEN CILACAP \\ (Studi Tentang Efektifitas Keputusan Jaksa Agung RI Nomor : Kep152/A/JA/10/2015) \\ Oleh: HERIANTO YUDHISTIRO WIBOWO SOERYO PUTRO BHAROTO ${ }^{1}$
}

\begin{abstract}
TP4 is an Attorney General's innovation to eradicate corruption. Its function and role to guard and secure national strategic projects. This research is aimed at knowing and analyzing the effectiveness of the role of the Government Guards and Safeguards and Regional Development (TP4D) in preventing corruption in the Cilacap Regency. In addition, it is also to find out and analyze the constraints of the Government Guard and Regional Development Guards and Team (TP4D) in preventing corruption in Cilacap Regency. The study used a sociological juridical approach, with secondary data sources and quantitative analysis.

The results showed that, the role of the Government Guards and Regional Development Guards in preventing corruption in Cilacap Regency could be said to be quite effective, namely the Government Guards and Regional Safeguards and TP4D passively guarding, securing and supporting the success of the administration and development, namely Government Guards and Safeguards and Regional Development (TP4D) only when requested. Not all aspects of regional development are escorted by the Cilacap District Attorney and Regional Development Guards and Safety Team (TP4D), because there are other supervisory organizations such as user accounts, APIP and the internal organization of regional government. The Cilacap District Attorney Office basically acts as an effort to prevent corruption, so the Attorney General's Office will take firm action even proposing that it be stopped in the cultivator through a mechanism that is determined, if there is a procedural error we will take further action, because this is public money, and must be carried out correctly. The Cilacap District Attorney's Office escorted the Cilacap Regional Hospital renovation building construction project to the end and decreased corruption corruption cases in Cilacap Regency. The obstacle of the Government and Regional Development Guards and Security Teams (TP4D) in preventing corruption in Cilacap Regency is that it is still not well known about the TP4D duties and functions, there are still irregularities committed by the Cilacap District Government despite the assistance and socialization by TP4D and SKPD, and still not all are interested or willing to cooperate with TP4D to guard against development within the scope of the SKPD.

Kyewords: to eradicate corruption, Government Guards and Safeguards and Regional Development,
\end{abstract}

\begin{abstract}
ABSTRAK
TP4 merupakan inovasi Kejaksaan untuk memberantas korupsi. Fungsi dan perannya untuk mengawal dan mengamankan proyek strategis nasional. Penelitian ini ditujukan untuk mengetahui dan menganalisis efektivitas peran Tim Pengawal dan Pengaman Pemerintahan dan Pembangunan Daerah (TP4D) dalam mencegah tindak pidana korupsi di Kabupaten Cilacap. Selain itu juga untuk mengetahui dan menganalisis kendala Tim Pengawal dan Pengaman Pemerintahan dan Pembangunan Daerah (TP4D) dalam mencegah tindak pidana korupsi di Kabupaten Cilacap. Penelitian menggunakan metode pendekatan yuridis sosiologis, dengan sumber data sekunder serta analisis kuantitatif.
\end{abstract}

\footnotetext{
${ }^{1}$ Kejaksaan Negeri Cilacap, Lanang.yudhistira@ gmail.com
} 


\section{3 | Jurnal Idea Hukum \\ Vol. 5 No. 1 Maret 2019 \\ Magister Hukum Fakultas Hukum Universitas Jenderal Soedirman}

Hasil penelitian menunjukan bahwa, peran Tim Pengawal dan Pengaman Pemerintahan dan Pembangunan Daerah (TP4D) dalam mencegah tindak pidana korupsi di Kabupaten Cilacap dapat dikatakan cukup efektif yaitu Tim Pengawal dan Pengaman Pemerintahan dan Pembangunan Daerah (TP4D) pasif mengawal, mengamankan dan mendukung keberhasilan jalannya pemerintahan dan pembangunan yaitu Tim Pengawal dan Pengaman Pemerintahan dan Pembangunan Daerah (TP4D) hanya apabila diminta. Tidak semua aspek pembangunan daerah dikawal oleh Tim Pengawal dan Pengaman Pemerintahan dan Pembangunan Daerah (TP4D) Kejaksaan Negeri Cilacap, karena terdapat organisasi pengawas lainnya seperti Pengguna anggara, APIP dan perangkat organisasi internal pemerintahan daerah. Kejaksaan Negeri Cilacap pada dasarnya sebagai upaya pencegahan terjadinya tipikor, maka Kejaksaan akan menindak tegas bahkan mengusulkan untuk di hentikan dalam penggarapaannya melalui mekanisme yang di tetapkan, bila ternyata terjadi kesalahan prosedur kami akan melakukan tindakan lebih lanjut, karena ini uang rakyat, dan harus di laksanakan dengan benar. Kejaksaan Negeri Cilacap mengawal proyek pembangunan gedung renovasi RSUD Cilacap sampai akhir dan menurunnya kasus-kasus korupsi korupsi di Kabupaten Cilacap. Kendala Tim Pengawal Dan Pengaman Pemerintahan dan Pembangunan Daerah (TP4D) dalam mencegah tindak pidana korupsi di Kabupaten Cilacap yaitu masih belum dikenal secara menyeluruh mengenai tupoksi TP4D, masih terdapat penyimpangan yang dilakukan oleh jajaran Pemerintah Daerah Kabupaten Cilacap walaupun telah dilakukan pendampingan dan sosialisasi oleh TP4D dan SKPD, dan masih belum semua tertarik atau mau bekerja sama dengan TP4D untuk melakukan pengawalan terhadap pembangunan dalam lingkup SKPD tersebut

\section{A. Latar Belakang Masalah}

Kejaksaan Agung membentuk unit kerja baru untuk mengamankan program pembangunan pemerintah dari praktik korupsi. Unit kerja baru itu bernama Satuan Tugas (Satgas) Khusus Tim Pengawal Pengaman Pemerintah dan Pembangunan Pusat (TP4P) dan Tim Pengawal Pengaman Pemerintah dan Pembangunan Daerah (TP4D). Jaksa Agung Muda Intelijen (Jamintel) Adi Toegarisman telah melantik 31 anggota untuk mengisi satuan tugas tersebut.

Keberadaan Satgas yang akan dikembangkan menjadi direktorat pencegahan di Kejaksaan Agung dinilai sejumlah pihak tidak akan efektif dan hanya akan menghambur-hamburkan anggaran. Kejaksaan justru disarankan tidak perlu membentuk unit kerja baru, namun mengoptimalkan kerja jaksa bidang intelijen untuk pencegahan.

TP4 merupakan inovasi

Kejaksaan untuk memberantas korupsi. Fungsi dan perannya untuk mengawal dan mengamankan proyek strategis nasional. Tim ini untuk memberikan pendampingan hukum. Selain itu Kejaksaan ke depan lebih mengedepankan upaya pencegahan. Pembentukan TP4 mengacu pada Inpres Nomor 7 Tahun 2015 mengenai Aksi Pencegahan dan Pemberantasan Korupsi. Pengawalan yang dilakukan TP4 agar penyerapan anggaran bisa transparan dan lebih baik. Dengan demikian, pejabat pemerintah dan pelaku bisnis bisa lebih nyaman menyelesaikan proyek pembangunan. 
B. Perumusan Masalah

Berdasarkan latar belakang masalah di atas, maka dapat dirumuskan permasalahan :

1. Bagaimanakah efektivitas peran Tim Pengawal dan Pengaman Pemerintahan dan Pembangunan Daerah (TP4D) dalam mencegah tindak pidana korupsi di Kabupaten Cilacap ?

2. Apa yang menjadi kendala Tim Pengawal dan Pengaman Pemerintahan dan Pembangunan Daerah (TP4D) dalam mencegah tindak pidana korupsi di Kabupaten Cilacap ?

\section{Metode Penelitian}

1. Metode : Yuridis Sosiologis Pendekatan

2. Spesifikasi : Deskriptif Penelitian

3. Jenis data : Data primer dan data sekunder

4. Metode : Wawancara, Pengambilan observasi, dan Data studi kepustakaan atau studi dokumen.

5. Teknik : Teks naratif. Penyajian Data

6. Analisa Data : Kualitatif.

\section{Hasil dan Pembahasan}

1. Efektivitas Peran Tim Pengawal Dan Pengaman Pemerintahan Dan
Pembangunan Daerah (TP4D) Dalam Mencegah Tindak Pidana Korupsi Di Kabupaten Cilacap

Menurut pendapat yang dikemukakan Lawrence M Friedman, bahwa sistem hukum meliputi : substansi, struktur, dan budaya hukum, masing-masing elemen tersebut uraianya adalah sebagai berikut :

a. Substansi hukum substansi hukum adalah aturan, norma, dan pola tingkah laku manusia yang berada dalam sistem itu. Pengertian substansi tidak hanya terbatas pada hukum yang tertulis, tetapi juga hukum yang hidup dan berlaku dalam masyarakat:

b. Struktur hukum struktur hukum adalah yang merupakan institusionalisasi kedalam entitas sentitas hukum, seperti pengadilan tingkat pertama, banding dan kasasi, serta integrated criminal justice system:

c. Budaya hukum

Budaya hukum adalah sikap-sikap dan nilai-nilai yang berhubungan dengan hukum, yang terkait dengan tingkah laku yang berhubungan dengan lembaganya, 


\section{5 | Jurnal Idea Hukum}

Vol. 5 No. 1 Maret 2019

Magister Hukum Fakultas Hukum Universitas Jenderal Soedirman

baik secara positif maupun negatif. ${ }^{2}$

Dalam rangka mendukung penyelenggaraan pemerintahan dan pembangunan nasional di pusat dan daerah melalui pengawalan dan pengamanan, serta upaya mencegah timbulnya penyimpangan dan kerugian negara, maka Kejaksaan Republik Indonesia mengeluarkan Instruksi Jaksa Agung Republik Indonesia Nomor: INS001/A/JA/10/2015 tentang Pembentukan dan Pelaksanaan Tugas Tim Pengawal, Pengaman Pemerintahan dan Pembangunan Pusat (TP4P) dan Daerah (TP4D).

Dalam rangka melaksanakan Keputusan Jaksa Agung Republik Indonesia Nomor: KEP-152/A/JA/10/2015 tentang Pembentukan Tim Pengawal, Pengaman Pemerintahan dan Pembangunan (TP4), maka Kejaksaan Republik Indonesia juga mengeluarkan Instruksi Jaksa Agung Republik Indonesia Nomor: INS001/A/JA/10/2015 tentang Pembentukan dan Pelaksanaan Tugas Tim Pengawal, Pengaman Pemerintahan dan Pembangunan

2 Ade Maman Suherman, 2004.Pengantar Perbandingan Sistem Hukum. Raja Grafindo Persada, Jakarta. hal. 11-13
Pusat (TP4P) dan Daerah(TP4D). Pembentukan Tim Pengawal, Pengaman Pemerintahan dan Pembangunan Pusat (TP4P) dan Daerah (TP4D) ini disebabkan karena pada tahun 2015 lalu penyerapan anggaran yang dialami oleh pemerintah pusat maupun daerah sangat rendah.

Dengan dibentuknya Tim Pengawal, Pengaman Pemerintahan dan Pembangunan Daerah (TP4D), diharapkan setiap pejabat daerah dari Satuan Kerja Perangkat Daerah (SKPD) bisa meminta pendampingan untuk penggunaan anggaran keuangan daerah, sehingga semuanya bisa tepat sasaran dan program pembangunan bisa berjalan dengan baik. Pendampinganya yang diberikan oleh Tim Pengawal, Pengaman Pemerintahan dan Pembangunan Daerah (TP4D) kepada pejabat daerah dari Satuan Kerja Perangkat Daerah (SKPD) ini sampai pada pengawasan hasil pembangunan yang dilakukan.

Peran diartikan pada karakterisasi yang disandang untuk dibawakan oleh seorang aktor dalam sebuah pentas drama, yang dalam konteks sosial peran diartikan sebagai suatu fungsi yang dibawakan seseorang ketika menduduki suatu posisi 
dalam struktur sosial. Peran seorang aktor adalah batasan yang dirancang oleh aktor lain, yang kebetulan sama- sama berada dalam satu penampilan/ unjuk peran (role perfomance). ${ }^{3}$

Ketentuan peranan adalah pernyataan formal dan terbuka tentang perilaku yang harus ditampilkan seseorang dalam membawa perannya. Gambaran peranan adalah suatu gambaran tentang perilaku yang secara actual di tampilkan seseorang dalam membawakan perannya, sedangkan harapan peran adalah harapan orang-orang terhadap prilaku yang ditampilkan seseorang dalam menjalankan perannya.

Presiden mengeluarkan Instruksi Presiden Nomor 7 Tahun 2015 tentang Aksi Pencegahan dan Pemberantasan Korupsi Tahun 2015 pada tanggal 6 Mei 2015. Instruksi Presiden Nomor 7 Tahun 2015 tentang Aksi Pencegahan dan Pemberantasan Korupsi Tahun 2015 dimaksudkan untuk meningkatkan upaya pencegahan terjadinya tindak pidana korupsi di instansi pemerintahan yang perlu didukung dan dilaksanakan

3 Edy Suhardono, 1994, Teori Peran (Konsep, Derivasi dan Implikasinya), PT Gramedia Pustaka Utama, Jakarta, hal. 3 secara terencana dan sungguhsungguh sehingga kegiatan pencegahan korupsi yang dilakukan oleh Kejaksaan Republik Indonesia dapat berlangsung dengan efektif dan optimal.

Substansi berkaitan dengan produk dari undangundang sendiri. menurut Friedman sebagaimana yang telah dikutip Soerjono Soekanto bahwa, the substance is composed of substanctive rules and rules about how institutions should be have. ${ }^{4}$ Jadi, yang dimaksud substansi menurut Friedman adalah aturan, norma, dan pola perilaku yang nyata manusia yang berada dalam sitem itu. Substansi disini termasuk pula the living law (hukum yang hidup) dan tidak hanya aturan yang ada dalam kitab undang-undang atau law in the book.

Dalam menerjemahkan substansi hukum, ternyata Lawrence $M \quad$ Friedman menggunakan teori H.L.A Hart, ia mengemukakan, bahwa:

Substansi tersusun dari peraturan-peraturan dan ketentuan mengenai bagaimana institusi-institusi itu harus berperilaku. H. L.

${ }^{4}$ Soerjono Soekanto, 2011, Faktor-Faktor yang Mempengaruhi Hukum, PT.Raja Grafindo Persada, Jakarta, hal. 8 


\section{7 | Jurnal Idea Hukum \\ Vol. 5 No. 1 Maret 2019 \\ Magister Hukum Fakultas Hukum Universitas Jenderal Soedirman}

A. Hart berpendapat bahwa, ciri khas suatu sistem hukum adalah kumpulan ganda dari peraturanperaturan. Suatu sistem hukum adalah kesatuan dari "peraturanperaturan primer" dan "peraturan-peraturan sekunder." Peraturan primer adalah normanorma perilaku; peraturan sekunder adalah norma mengenai norma-norma ini, bagaimana memutuskan apakah semua itu valid, bagaimana

memberlakukannya, Tentu saja, baik peraturan primer maupun sekunder adalah sama-sama output dari sebuah sistem hukum. Semua itu merupakan cara menjelaskan perilaku sistem hukum bila dilihat secara menyilang. Para pihak yang berperkara akan berperilaku atas dasar substansi yang membuahkan perkiraan yang direspon mereka. ${ }^{5}$

Tim Pengawal, Pengaman

Pemerintahan dan Pembangunan

(TP4) berdasarkan Keputusan

Jaksa Agung Republik Indonesia

Nomor: KEP-152/A/JA/10/2015

tentang Pembentukan Tim

Pengawal, Pengaman

Pemerintahan dan Pembangunan

(TP4) mempunyai tugas dan

fungsi sebagai berikut:

a. Mengawal, mengamankan dan mendukung keberhasilan jalannya pemerintahan dan

5 Lawrence M. Friedman, 2011, Sistem Hukum Perspektif Ilmu Sosial, Diterjemahkan oleh M. Khozim, Nusamedia, Bandung, hal. 16 pembangunan melalui upayaupaya pencegahan/preventif dan persuasif baik di tingkat pusat maupun daerah sesuai wilayah hukum penugasan masing-masing dengan caracara:

1) Memberikan penerangan hukum di lingkungan instansi pemerintah, BUMN, BUMD, dan pihak lain terkait materi tentang perencanaan, pelelangan, pelaksanaan pekerjaan, pengawasan pelaksanaan pekerjaan, perijinan, pengadaan barang dan jasa, tertib administrasi dan tertib pengelolaan keuangan negara.

2) Melakukan diskusi atau pembahasan bersama instansi pemerintah, BUMN, BUMD untuk mengidentifikasi

permasalahan yang dihadapi dalam penyerapan anggaran dan pelaksanaan pembangunan.

3) Memberikan penerangan dan penyuluhan hukum baik atas inisiatif TP4 maupun atas permintaan pihak-pihak yang memerlukan yang tempat dan waktu pelaksanaannya ditetapkan berdasarkan kesepakatan dan sesuai kebutuhan.

4) TP4 dapat melibatkan instansi atau pihak lain yang memiliki kapasitas, kompetensi dan relevan dengan materi penerangan dan penyuluhan hukum yang akan disampaikan kepada instansi pemerintah, BUMN, dan BUMD.

b. Dapat memberikan pendampingan hukum dalam setiap tahapan program pembangunan dari awal sampai akhir, berupa: 
1) Pembahasan hukum dari sisi penerangan regulasi, peraturan perundang-undangan, mekanisme dan prosedur dengan pejabat pengelola anggaran atas permasalahan yang dihadapi dalam hal penyerapan anggaran.

2) Pendapat hukum dalam tahapan perencanaan, pelelangan, pelaksanaan pekerjaan, pengawasan pelaksanaan pekerjaan, pengadaan barang dan jasa baik atas inisiatif TP4 maupun atas permintaan instansi dan pihak pihak yang memerlukan.

c. Melakukan koordinasi dengan Aparat Pengawasan Intern Pemerintah untuk mencegah terjadinya penyimpangan yang berpotensi menghambat, menggagalkan dan menimbulkan kerugian bagi keuangan negara.

d. Bersama-sama melakukan monitoring dan evaluasi pelaksanaan pekerjaan dan program pembangunan.

e. Melaksanakan penegakan hukum represif ketika ditemukan bukti permulaan yang cukup setelah dilakukan koordinasi dengan Aparat Pengawasan Intern Pemerintah tentang telah terjadinya perbuatan melawan hukum, penyalahgunaan kewenangan dan/atau perbuatan lainnya yang berakibat menimbulkan kerugian bagi keuangan negara. ${ }^{6}$

6 Keputusan Jaksa Agung Republik Indonesia Nomor: KEP152/A/JA/10/2015 tentang Pembentukan Tim Pengawal, Pengaman Pemerintahan dan Pembangunan (TP4)

Berdasarkan hasil wawancara dengan $M$. Arief Adbillah selaku Ketua TP4D Kejaksaan Negeri Cilacap/ Kasi Intel yang pada intinya TP4D adalah tim yang melakukan tugas Pengawalan dan Pengamanan pemerintahan dan pembangunan. TP4D ini sifatnya pencegahan, Kejaksaan sudah memberikan warning sejak dini untuk pencegahan tindak pidana korupsi. ${ }^{7}$ M. Arief Adbillah selaku Ketua TP4D Kejaksaan Negeri Cilacap/ Kasi Intel mendefinisikan TP4D sebagai tim yang melakukan tugas Pengawalan dan Pengamanan pemerintahan dan pembangunan yang sifatnya pencegahan. Kejaksaan berfungsi sebagai early warning sejak dini untuk pencegahan tindak pidana korupsi. Pencegahan tipikor yang lakukan Kejaksaan tidak digubris oleh kepala desa/ pejabat suatu instansi maka tidak ada pilihan mereka akan ditindak tegas.

Menurut Friedman yang dikutip oleh Achmad Ali bahwa, the structure of a system is its skeletal frame work; it is the permanent shape, the institutional body of the system the tough,

\footnotetext{
7 Wawancara dengan M. Arief Adbillah selaku Ketua TP4D Kejaksaan Negeri Cilacap/ Kasi Intel di Kejaksaan Negeri pada tanggal 3 Juli 2018.
} 
1339 | Jurnal Idea Hukum

Vol. 5 No. 1 Maret 2019

Magister Hukum Fakultas Hukum Universitas Jenderal Soedirman

rigid bones that keep the process flowing within bounds. Jadi struktur adalah kerangka atau rangkanya, bagian yang tetap bertahan, bagian yang memberi semacam bentuk dan batasan terhadap keseluruhan. Dalam sistem hukum yang berlaku di Indonesia, maka yang mencakup pada unsur struktur adalah struktur institusi-institusi penegak hukum, seperti kepolisian, kejaksaan, pengadilan, dan lembaga pemasyarakatan. ${ }^{8}$

Struktur hukum adalah yang merupakan institusionalisasi kedalam entitas sentitas hukum, seperti pengadilan tingkat pertama, banding dan kasasi, serta integrated criminal justice system. Berdasarkan gambaran struktur hukum, hadirnya TP4D dalam memberikan penerangan, pendampingan dan pendapat hukum dalam penyelenggaran proyek pembangunan juga dimaksudkan untuk menghilangkan kekhawatiran aparat pemerintahan khususnya pejabat publik dalam menentukan dan mengeluarkan kebijakan/keputusan atau tindakan lain yang bersinggungan dengan percepatan pelaksanaan

${ }^{8}$ Achmad Ali, 2002, Keterpurukan Hukum di Indonesia, Ghalia Indonesia, Jakarta, hal. 8 pembangunan. Dengan demikian stigma kebijakan pejabat publik telah dikriminalisasi dapat dihindari bila masing-masing pihak baik TP4D dan Pejabat publik dapat bersinergi berdasarkan tugas dan fungsinya masingmasing.

Ruang lingkup Pengawalan dan Pengamanan pemerintahan dan pembangunan meliputi:

a. Pencegahan/preventi $f$ dan persuasif;

b. Pendampingan Hukum;

c. melakukan Koordinasi dengan APIP dan/atau instansi terkait;

d. melakukan Monitoring dan Evaluasi; dan

e. melakukan penegakan hukum represif.

Apabila dilihat dari tugas dan kewenangannya, maka Tim Pengawal, Pengaman Pemerintahan dan Pembangunan Daerah (TP4D) memiliki kewenangan hanya sebatas melakukan pengawalan dan pengamanan jalannya pemerintahan dan pembangunan melalui upaya-upaya preventif dan melakukan penerangan serta penyuluhan hukum dalam setiap 
tahapan program pembangunan dari awal sampai akhir. Sedangkan untuk tugas pengawasan, monitoring dan evaluasi pelaksanaan pekerjaan dan program pembangunan daerah, Tim Pengawal, Pengaman Pemerintahan dan Pembangunan Daerah (TP4D) tetap harus melakukan koordinasi dengan Aparat Pengawas Internal Pemerintah (APIP), termasuk Badan Pengawas Keuangan dan Pembangunan (BPKP) untuk mencegah terjadinya penyimpangan yang berpotensi menghambat, menggagalkan dan menimbulkan kerugian bagi keuangan negara.

Berdasarkan hasil wawancara dengan Bobi Heryanto selaku Sekretaris TP4D Kejaksaan Negeri Cilacap/ Kasi Pidana Khusus, TP4D berfungsi mengawal proyek-proyek pembangunan pemerintah. Misalnya pada proyek pengerjaan lanjutan jalan jembatan yang terletak di daerah Penthus, Cimanggu Kecamatan Cipari. Kejaksaan Negeri Cilacap bertugas dalam hal pengawalan dan pengamanan dilakukan terhadap pekerjaan pembangunan yang akan dan/atau sedang dikerjakan pada lingkungan

Pemerintah
Pusat/Kementerian/Lembaga/Pe merintah Daerah/BUMN/ BUMD. Hal ini merupakan pencegahan/preventif dan persuasif dalam rangka mengawal, mengamankan dan mendukung keberhasilan jalannya pemerintahan dan pembangunan dilakukan dengan cara:

a. memberikan Penerangan Hukum di lingkungan Pemerintah

Pusat/Kementerian/Lembaga/

Pemerintah

Daerah/BUMN/BUMD terkait materi tentang perencanaan, pelelangan, pelaksanaan pekerjaan, pengawasan pelaksanaan pekerjaan, perizinan, pengadaan barang dan jasa, tertib administrasi dan tertib pengelolaan keuangan negara;

b. melakukan Diskusi atau pembahasan bersama lingkungan Pemerintah Pusat/Kementerian/Lembaga/ Pemerintah

Daerah/BUMN/BUMD untuk mengidentifikasi permasalahan yang dihadapi dalam penyerapan anggaran dan pelaksanaan pembangunan;

c. memberikan Penerangan Hukum dan Penyuluhan Hukum atas inisiatif TP4 maupun atas permintaan pihak yang memerlukan yang tempat dan waktu pelaksanaannya ditetapkan berdasarkan kesepakatan dan sesuai kebutuhan;

d. TP4 dapat melibatkan instansi atau pihak lain yang memiliki kapasitas, kompetensi dan relevan dengan materi Penerangan Hukum dan Penyuluhan Hukum yang akan disampaikan kepada lingkungan Pemerintah Pusat/ 


\section{1 | Jurnal Idea Hukum \\ Vol. 5 No. 1 Maret 2019 \\ Magister Hukum Fakultas Hukum Universitas Jenderal Soedirman}

Kementerian/Lembaga/Pemeri ntah Daerah/ BUMN/ BUMD.

Berdasarkan uraian di atas, maka gambaran pelaksanaan peran TP4D Kejaksaan Negeri Cilacap lebih ditujukan kepada dua bidang yaitu pengawalan dan penyuluhan hukum. Pengawalan ditujukan agar program-program pembangunan berjalan dengan baik, yaitu dengan melakukan pendampingan hukum, melakukan koordinasi dengan instansi terkait, serta melakukan monitoring dan evaluasi, bahkan melakukan teguran. Gambaran pelaksanaan peran TP4D Kejaksaan Negeri Cilacap bersifat konkrit dan individual. Konkrit berarti jelas tujuannya, jelas objek yang diawasinya, dan individual berarti jelas subjeknya baik instansi pemerintah ataupun kontraktor. Selain pengawalan gambaran peranan TP4D Kejaksaan Negeri Cilacap juga ditujukan untuk melakukan penyuluhan dan penerangan hukum. Penyuluhan tidak bersifat konkrit dan individual, tetapi abstrak karena berupa penambahan pengetahuan bagi masyarakat atau instansi tertentu.

Manfaat pengawalan TP4D Kejaksaan Negeri Cilacap yaitu proyek-proyek pembangunan tersebut aman dari segala bentuk tindakan mark up anggaran sehingga mencegah adanya penyalahgunaan uang rakyat. Pengawalan tentunya berguna agar bisa mengawasi secara langsung supaya tidak ada indikasi korupsi, karena bila terjadi penyimpangan hukum yang akan bertindak. Selain itu dengan adanya pengawalan diharapkan agar bahan atau matrial yang di gunakan sesuai dengan yang di harapkan, sehingga dapat bertahan dan tidak terkesan asal asalan.

Lawrence M. Friedman menyebut subsistem yang terakhir adalah kultur hukum atau budaya hukum. Friedman sebagaimana dikutip oleh Soerjono Soekanto ${ }^{9}$, menyatakan mengenai kultur bahwa the legal culture, system-their beliefs, values, ideas, and expectations. (kultur hukum merupakan sikap manusia terhadap hukum, sistem hukum-kepercayaan, nilai, pemikiran, serta harapannya). Legal culture refers, then, to those part of general culture-customs, opinions, ways of doing and thinking that bend social forces to ward or away from the law and in particular ways. (Kultur hukum adalah suasana pikiran sosial dan kekuatan sosial yang menentukan

${ }^{9}$ Soerjono Soekanto, $O p$ cit., hal. 9 
bagaimana hukum digunakan, dihindari, atau disalahgunakan).

Terkait dengan pengaruh pengawalan terhadap tindak pidana korupsi, M. Berdasarkan wawancara dengan Arief Adbillah selaku Ketua TP4D Kejaksaan Negeri Cilacap/ Kasi Intel yang pada intinya bahwa, peran TP4D cukup efektif, sejak ada program pengawalan, kasus-kasus tipikor cenderung turun, pada tahun 2014 kita melakukan penuntutan hingga 6 kasus tindak pidana korupsi, kemudian tahun 2016 turun menjadi tiga kasus, dan tahun 2017 hanya 1 kasus. Hal ini disebabkan kejaksaan dapat melakukan deteksi dini, sehingga tidak terjadi korupsi. Hal ini didukung oleh hasil wawancara yang dilakukan penulis kepada Agus Suhartanto Anggota TP4D Kejaksaan Negeri Cilacap/ Jaksa Fungsional yang secara nasional Tim Pengawal dan Pengaman Pemerintahan dan Pembangunan Daerah (TP4D) telah memberikan hasil guna mencegah tindak pidana korupsi. Di kabupaten Cilacap sendiri penanganan tipikor yang maju hingga sampai tahap tututan menurun drastis.

$$
\text { Kejaksaan berfungsi }
$$

memberikan peringatan sejak dini untuk pencegahan tindak pidana korupsi. Namun demikian pencegahan tipikor yang lakukan Kejaksaan tidak melemah, ketika tetap terjadi tindak pidana korupsi maka akan ditindak tegas. TP4D yang diketuai oleh Kasi Intel berfungsi memberikan penyuluhan hukum, kemudian bagaimana membuat laporan pertanggungjawaban penggunaan dana ADD yang baik sehingga kebocoran dapat dihindari. Hingga tahun 2017 TP4P sebagai pencegahan dinilai cukup efektif.

\section{Kendala Tim Pengawal Dan Pengaman Pemerintahan Dan Pembangunan Daerah (TP4D) Dalam Mencegah Tindak Pidana Korupsi Di Kabupaten Cilacap}

Aparat penegak hukum dan juga pemerintah masih belum mengenal secara menyeluruh mengenai tupoksi TP4D. Hal ini tentunya menjadi kendala dalam proses kordinasi antara kejaksaan dengan penegak hukum dan antara kejaksaan dengan pemerintah. Ditinjau dari struktur ketatanegaraan, Tim Pengawal, Pengaman Pemerintahan dan Pembangunan Daerah (TP4D) bukan merupakan lembaga pengawasan negara seperti BPK dan BPKP, karena dibentuk berdasarkan Pidato Presiden RI 


\section{3 | Jurnal Idea Hukum \\ Vol. 5 No. 1 Maret 2019 \\ Magister Hukum Fakultas Hukum Universitas Jenderal Soedirman}

pada Upacara Peringatan Hari

Bhakti Adhyaksa ke 55 tanggal 22 Juli 2015, Keputusan Jaksa

Agung Republik Indonesia

Nomor: KEP-152/A/JA/10/2015

tentang Pembentukan Tim

Pengawal, Pengaman

Pemerintahan dan Pembangunan

(TP4), dan Instruksi Jaksa Agung

Republik Indonesia Nomor: INS001/A/JA/10/2015 tanggal 5

Oktober 2015 tentang

Pembentukan dan Pelaksanaan

Tugas Tim Pengawal dan

Pengaman Pemerintahan dan

Pembangunan Pusat (TP4P) dan

Daerah (TP4D).

Kedudukan Tim Pengawal,

Pengaman Pemerintahan dan

Pembangunan Daerah (TP4D)

diharapkan bisa menjadi lembaga

independen dalam melakukan

pengawasan pembangunan

daerah. Namun perlu diingat, bahwa Tim Pengawal, Pengaman

Pemerintahan dan Pembangunan

Daerah (TP4D) dalam menjalankan tugas dan

kewenangannya tetap harus berkoordinasi dengan lembaga pengawasan negara lainnya, termasuk BPK, BPKP, Itjen dan Itda.

Kendala lainnya yang
dihadapi Tim Pengawal Dan
Pengaman Pemerintahan dan
Pembangunan Daerah (TP4D)

Kejaksaan Negeri Cilacap yaitu masih terdapat penyimpangan yang dilakukan oleh jajaran Pemerintah Daerah Kabupaten Cilacap walaupun telah dilakukan pendampingan dan sosialisasi oleh TP4D dan SKPD. Berdasarkan hal tersebut, maka komitmen dan upaya dalam pencegahan dan pemberantasan korupsi di daerah sangatlah lemah, walaupun telah dilakukan pendampingan dan sosialisasi oleh TP4D dan SKPD masih terjadi tindak pidana korupsi.

Komitmen dan upaya dalam pencegahan dan pemberantasan korupsi selama ini selalu menjadi prioritas pemerintah. Berbagai upaya telah dilakukan oleh Pemerintah seperti penataan kebijakan dan regulasi, baik berupa instruksi/arahan maupun peraturan perundangundangan, perbaikan tata kelola pemerintahan, pembenahan proses pelayanan publik, transparansi dan akuntabilitas pengelolaan keuangan negara, termasuk penyelamatan keuangan/ aset negara.

Pada tingkat internasional, Pemerintah juga aktif terlibat dalam berbagai inisiatif global untuk memerangi korupsi. Salah satunya melalui ratifikasi Konvensi Perserikatan Bangsa- 
Bangsa Melawan Korupsi (United

Nations Conuention Against

Comtption) melalui Undang-

Undang Nomor 7 Tahun 2006

tentang Pengesahan United

Nations Conuention Against 2003

(Konvensi Perserikatan Bangsa-

Bangsa Anti Korupsi, 2003).

Sebagai konsekuensi dari

ratifikasi tersebut, Pemerintah

Indonesia telah menetapkan

Peraturan Presiden Nomor 55

Tahun 2012 tentang Strategi

Nasional Pencegahan dan

Pemberantasan Korupsi Jangka

Panjang Tahun 2012-2025 dan

Jangka Menengah Tahrtn 2012-

2014 (Stranas PPK). Strategi yang terdapat dalam Stranas PPK meliputi strategi pencegahan, strategi penegakan hukum, strategi harmonisasi peraturan perundang-undangan, strategi kerjasama internasional dan penyelamatan aset, strategi dan budaya anti korupsi, serta strategi mekanisme pelaporan, yang dalam hanya menitikberatkan pada upaya pencegahan korupsi.

Komitmen dan upaya
dalam pencegahan dan
pemberantasan korupsi ternyata tidak diikuti oleh komitmen pemerinah daerah. Sudah seharusnya inisiatif pencegahan korupsi tidak hanya melalui
Stranas PPK, melainkan juga dari pemerintah daerah. Hal ini menyebabkan upaya pencegahan korupsi belum bersinergi secara optimal sehingga dibutuhkan upaya konsolidasi yang lebih efektif atas berbagai inisiatif pencegahan korupsi oleh kementerian, lembaga, pemerintah daerah, dan pemangku kepentingan lainnya. Disamping itu, upaya konsolidasi seyogranya tidak hanya terbatas pada kementerian, lembaga, dan pemerintah daerah sebagaimana ditentukan dalam Stranas PPK, melainkan perlu juga melibatkan Komisi Pemberantasan Korupsi sebagai lembaga khusus yang berdasarkan undang-undang diberikan kewenangan koordinasi dan supervisi dalam pencegahan dan pemberantasan korupsi.

Kendala lain dalam pelaksanaan peran Tim Pengawal Dan Pengaman Pemerintahan dan Pembangunan Daerah (TP4D) Kejaksaan Negeri Cilacap yaitu masih belum semua tertarik atau mau bekerja sama dengan TP4D untuk melakukan pengawalan terhadap pembangunan dalam lingkup SKPD tersebut. Hal ini tentunya menjadi kendala Tim Pengawal Dan Pengaman Pemerintahan dan Pembangunan Daerah 


\section{5 | Jurnal Idea Hukum}

Vol. 5 No. 1 Maret 2019

Magister Hukum Fakultas Hukum Universitas Jenderal Soedirman

(TP4D) Kejaksaan Negeri Cilacap karena setiap SKPD tidak di wajibkan bekerjasama dengan Tim Pengawal Dan Pengaman Pemerintahan dan Pembangunan Daerah (TP4D) Kejaksaan Negeri Cilacap oleh Pemerintah Daerah.

\section{G. Simpulan Dan Saran}

\section{Simpulan}

Berdasarkan

hasil

peneltian dan pembahasan yang dilakukan oleh penulis, maka dapat diambil suatu simpulan sebagai berikut:

a. Peran Tim Pengawal dan Pengaman Pemerintahan dan Pembangunan Daerah (TP4D) dalam mencegah tindak pidana korupsi di Kabupaten Cilacap dapat dikatakan cukup efektif yaitu didasarkan paa halhaal sebagai berikut:

1) Tim Pengawal dan Pengaman

Pemerintahan dan Pembangunan Daerah (TP4D) pasif mengawal, mengamankan dan mendukung keberhasilan jalannya pemerintahan dan pembangunan yaitu Tim Pengawal dan

Pengaman

Pemerintahan dan
Pembangunan Daerah (TP4D) hanya apabila diminta. Tidak semua aspek pembangunan daerah dikawal oleh Tim Pengawal dan

Pengaman

Pemerintahan dan Pembangunan Daerah (TP4D) Kejaksaan Negeri Cilacap, karena terdapat organisasi pengawas lainnya seperti Pengguna anggara, APIP dan perangkat organisasi internal pemerintahan daerah.

2) Tim Pengawal dan Pengaman

Pemerintahan dan Pembangunan Daerah (TP4D) aktif memberikan

penerangan hukum dilingkungan pemerintah desa, dan Dinas Pekerjaan Umum, serta SKPD lainnya.

3) Tim Pengawal dan Pengaman

Pemerintahan dan

Pembangunan Daerah (TP4D) aktif memberikan pendampingan hukum dalam setiap tahapan 
program pembangunan

dari awal sampai akhir.

Kejaksaan Negeri

Cilacap pada dasarnya

sebagai

upaya

pencegahan terjadinya

tipikor, maka Kejaksaan

akan menindak tegas

bahkan mengusulkan

untuk di hentikan dalam

penggarapaannya

melalui mekanisme

yang di tetapkan, bila

ternyata terjadi

kesalahan prosedur

kami akan melakukan

tindakan lebih lanjut,

karena ini uang rakyat,

dan harus di laksanakan

dengan benar.

Kejaksaan Negeri

Cilacap mengawal

proyek pembangunan

gedung renovasi RSUD

Cilacap sampai akhir.

4) Tim Pengawal dan

Pengaman

Pemerintahan dan

Pembangunan Daerah

(TP4D) Kejaksaan

Negeri Cilacap

melakukan upaya

teguran terhadap

proyek-proyek yang

terlambat dan ketidak

sesuaian material

proyek.
5) Proses monitoring dan evaluasi pekerjaan dan program pembangunan berjalan.

Proses monitoring dan evaluasi pekerjaan dan program pembangunan yang dilakukan Tim Pengawal dan Pengaman

Pemerintahan dan

Pembangunan Daerah

(TP4D) Kejaksaan

Negeri Cilacap berjalan cukup baik.

6) Melaksanakan

penegakkan hukum

represif ketika

ditemukan bukti

permulaan yang cukup

setelah dilakukan

koordinasi dengan

aparat pengawasan

intern pemerintah

tentang telah terjadinya

perbuatan melawan

hukum, penyalahgunaan

kewenangan dan/atau

perbuatan lainnya yang

berakibat menimbulkan

kerugian bagi keuangan

Negara. Sejak ada

program pengawalan,

kasus-kasus tipikor

cenderung turun, pada

tahun 2014 dilakukan penuntutan hingga 6

kasus tindak pidana 


\section{7 | Jurnal Idea Hukum}

Vol. 5 No. 1 Maret 2019

Magister Hukum Fakultas Hukum Universitas Jenderal Soedirman

korupsi, kemudian tahun

2016 turun menjadi tiga

kasus, dan tahun 2017

hanya 1 kasus

7) Menurunnya kasus-

kasus korupsi korupsi di

Kabupaten Cilacap.

b. Kendala Tim Pengawal Dan

Pengaman Pemerintahan dan

Pembangunan Daerah (TP4D)

dalam mencegah tindak pidana korupsi di Kabupaten Cilacap yaitu :

1) masih belum dikenal secara menyeluruh mengenai tupoksi TP4D,

2) masih terdapat oknum jajaran Pemerintah Daerah Kabupaten Cilacap yang tetap melakkukan penyimpangan walaupun telah dilakukan pendampingan dan sosialisasi oleh TP4D dan SKPD,

3) masih belum semua SKPD tertarik atau mau bekerja sama dengan TP4D untuk melakukan pengawalan terhadap pembangunan dalam lingkup SKPD tersebut.

\section{Saran}
a. Sebaiknya
dilakukan penyuluhan dan sosialisasi tugas pokok dan fungsi Tim

Pengawal dan Pengaman

Pemerintahan dan

Pembangunan Daerah (TP4D)

Kejaksaan Negeri Cilacap pada

setiap SKPD di Kabupaten

Cilacap.

b. Sebaiknya dibentuk MoU dan pakta integritas kepada setiap jajaran Pemerintahan Daerah dalam upaya pencegahan korupsi, khususnya dibidang pengadaan barang dan jasa. Dengan adanya MoU dan Pakta Integritas, maka Tim Pengawal dan Pengaman Pemerintahan dan Pembangunan Daerah (TP4D) Kejaksaan Negeri Cilacap dapat dengan leluasa membantu, mengawal dan memberi pendampingan hukum dalam program pembangunan daerah.

c. Sebaiknya terdapat pengawasan internal dan eksternal terhadap Tim Pengawal dan Pengaman Pemerintahan dan Pembangunan Daerah (TP4D) Kejaksaan Negeri Cilacap, agar tidak terjadi permufakatan jahat antara swasta dengan Kejaksaan terhadap proyek pembangunan di Kabupaten Cilacap. 


\section{DAFTAR PUSTAKA}

Ali, Achmad. 2002. Keterpurukan Hukum di Indonesia. Ghalia Indonesia. Jakarta.

Friedman, Lawrence M.. 2011. Sistem Hukum Perspektif IImu Sosial. Diterjemahkan oleh M. Khozim. Nusamedia. Bandung.

Soekanto, Soerjono. 2011. FaktorFaktor yang Mempengaruhi Hukum. PT.Raja Grafindo Persada. Jakarta.

Suhardono, Edy. 1994. Teori Peran (Konsep. Derivasi dan Implikasinya). PT Gramedia Pustaka Utama. Jakarta.

Suherman, Ade Maman. 2004. Pengantar Perbandingan Sistem Hukum. Raja Grafindo Persada. Jakarta. 